\title{
Sembrando un cuerpo nuevo. Performance $e$ interconexión en prácticas musicales "andinas" de Buenos Aires 1
}

\section{Building a New Body. Performance and Interconnection in "Andean" Musical Practices in Buenos Aires, Argentina}

\author{
por \\ Adil Podhajcer \\ Instituto de Altos Estudios (IDAES), Universidad de Buenos Aires (UBA), Consejo \\ Nacional de Investigaciones Científicas y Técnicas (CONICET), Argentina \\ adil.po@gmail.com
}

En el presente trabajo se abordan las prácticas de grupos de música andina en Buenos Aires en términos de los modos de recuperación de sonoridades y corporalidades tradicionales originales de Bolivia y Perú, enfocando dos aspectos centrales de su perdurabilidad. En primera instancia, cómo este tipo de prácticas producen, renuevan y actualizan en el discurso y la performancesentidos y emociones vinculados al "comunitarismo" y la "complementariedad" en tanto unidad-visión del mundo andino. En segunda instancia, cómo los sujetos resuelven con este discurso las estructuras musicales microconflictivas que surgen en la experiencia de la performance -en particular en la ronda como "ícono" de esta música-, las que apelan a lo emocional y cómo cultivan la sonoridad tradicional o "sonar bien" como parte de una nueva corporalidad.

Palabras clave: Música/performance/cuerpo/comunitarismo/sonoridad tradicional/reelaboración.

This paper is focused on groups practising Andean music in Buenos Aires, in terms of how the traditional sonorities and the corporeal features which originated in Bolivia and Peru are recovered. Two key features of the lasting permanence of these practices are emphasized. The first feature has to do with the way feelings and emotions linked with the "community" and the complement with one another-which make up the unity of the Andean vision of the world-are brought forth, renewed and updated both by means of the speech and the performance in these practices. The second feature has to do with the way the persons participating in these practices solve by means of this speech any microconflict related to the musical structures arising as part of the performance experience, particularly in the round as the "icon" of the music. These structures appeal to the emotions and to the care of the traditional sonorities aiming at "sounding well" as part of a new corporeal attitude.

Key words: music performance, body, community, traditional sonority, reelaboration.

${ }^{1}$ Este trabajo es resultado de mis investigaciones volcadas en mi Tesis Doctoral "Sonoridades en movimiento: Las performances de 'música andina' en Buenos Aires" dirigida por la Dra. Silvia Citro, financiada con una beca doctoral por la Universidad Nacional de Buenos Aires. Además ha sido ampliado gracias a una beca postdoctoral otorgada por CONICET y dirigida por el Dr. Luis Ferreira Makl. 


\section{INTRODUCCIÓN}

De acuerdo con diferentes autores ${ }^{2}$, desde fines de los 80 y especialmente en los 90 , se producen "cambios en el régimen de visibilización étnica" , sobre todo a partir de los desplazamientos desde la periferia hacia la ciudad capital. Paralelamente, las migraciones dejan de ser del tipo rural-rural -como en la primera etapa hacia Salta y Jujuy-, para ser de carácter rural-urbano e incluso urbano-urbano ${ }^{4}$. Estas migraciones son parte de nuevas estrategias orientadas a la búsqueda de mejorías laborales, documentación -frente a la amnistía de 1992/935- y la reconstrucción de sus identidades lejos del país de origen. El impacto migratorio desde las zonas fronterizas y periféricas hacia la capital y su nueva visibilidad coincidieron con el aumento de la desocupación entre 1992 y 1994, lo que incidió en los discursos que acusan a los inmigrantes de quitar el "trabajo para los argentinos" y de ser "ilegales"6.

Mientras esta visibilidad adquiere relevancia en la Capital Federal, surgen nuevas identificaciones e identidades que, para un grupo importante de estos inmigrantes de Bolivia y Perú, implican la "recuperación" de sus celebraciones y fiestas tradicionales, con las músicas y danzas de sus distintas regiones. En 1992, en el marco de una manifestación en conmemoración de los 500 años de la invasión europea en América, se pronuncian grupos de inmigrantes bolivianos y de argentinos dedicados a estas expresiones, lo que da lugar a la conformación de las primeras agrupaciones de música y danza andina, conocidas actualmente como "bandas de sikuris"' La inserción de los migrantes y el desarrollo de estas prácticas estéticas en la ciudad de Buenos Aires confluyeron en un proceso de transformación de las relaciones interculturales y en una revalorización de la identidad cultural boliviana y norteña (del norte argentino), así como del reconocimiento de los "pueblos originarios" y de cierta "identidad latinoamericana". La inserción de las comunidades migrantes implicará un acomodamiento de las relaciones y

2 Gavazzo 2005, Grimson 2005.

3 Grimson 2005: 15.

4 Grimson 2005:15.

5 Benencia y Karasik 1995; Grimson 2005, 2006.

6 Caggiano 2005. Dentro de este panorama, entre los bolivianos, las "formas de migrar" también implicaron el fortalecimiento de los vínculos personales de ayuda mutua, basados en "el parentesco, el paisanaje y la vecindad" (Benencia y Karasik, 1995; Mugraza 1985). El ayni, que numerosas familias bolivianas comparten, no se ha extendido a los peruanos, quienes al migrar solos y no entretejer redes parentales, permanecen ilegales y sin posibilidades de movilidad social u otras oportunidades laborales, que sean menos precarias. Ambas migraciones regionales constituyen un cultivo de experiencias que los adultos y jóvenes migrantes representan por medio de sus prácticas culturales, entendidas en contexto como espacios propios de expresión y representación social.

7 Las "bandas de sikuris" están compuestas por sopladores de siku, un instrumento de viento prehispánico ejecutado en los actuales países de Argentina, Chile, Bolivia, Perú y Ecuador. Según la región recibe distintas denominaciones y afinaciones y conforma familias de instrumentos que determinan estilos o géneros rítmicos específicos. 
prácticas entre "lo nuevo" y "lo original", con las nuevas proyecciones en la ciudad y las tradiciones regionales de sus pueblos ${ }^{8}$.

Dentro de este contexto, hacia 1995 comienzo a aprender la ejecución del siku, la quena y el charango ${ }^{9}$ en talleres, e integro desde entonces distintas "bandas de sikuris”. Estas vivencias simultáneas a mi formación como antropóloga constituyen una percepción reflexiva -en tanto intérprete e investigadora- de la experiencia etnográfica, que me permiten alcanzar inscripciones corporales de esas experiencias. Por esta razón, al igual que Merleau-Ponty, Jackson sostiene que el sujeto no está escindido del cuerpo. Por el contrario se trata de "un sujeto corporizado" en una "práctica corporizada" 10 , puesto que "pensar y comunicar a través del cuerpo precede y, en gran medida, siempre permanece más allá del habla"11. Por lo tanto, el movimiento corporal es en sí esa realidad, y no necesariamente simboliza otra.

Este enfoque vivencial basado en la adquisición corporal de pautas y comportamientos sociales y la percepción mimética de los mismos a partir del propio cuerpo han sido una fuente de análisis vital para este trabajo. En lo que se refiere al enfoque metodológico, dentro de las veinte bandas principales del universo sikuri de Buenos Aires se realizó un trabajo etnográfico con cinco de ellas, que presentan características distintivas. Una de ellas la integran en su mayoría jóvenes descendientes de bolivianos y peruanos, muchos de ellos pertenecientes a sectores populares. La otra está integrada por jóvenes descendientes de argentinos pertenecientes a la clase media baja mientras que la tercera está compuesta por personas adultas en su mayoría bolivianos y peruanos. Las últimas dos están integradas por personas de distinta procedencia, pero que en su mayoría descienden de argentinos. Se trata de jóvenes y adultos de clases populares con estudios profesionales en música occidental, variable que en los otros ensambles está prácticamente ausente.

Estas últimas dos bandas tienen como objetivo reproducir fielmente la música de comunidades de Bolivia, mientras que el resto de las bandas consideran el producto musical como un puente y un mediador hacia el abordaje de otros aspectos míticos y políticos vinculados históricamente con las culturas de los Andes Centrales. Estas diferencias y similitudes forman parte de los procesos de resignificación de las músicas andinas dentro de grupos que involucran relaciones interculturales entre migrantes bolivianos, descendientes y argentinos con diversas trayectorias artístico-culturales.

8 Con Turino (2003) compartimos la idea de considerar a estas comunidades culturales relocalizadas en una perspectiva cosmopolita y capitalista, con sus propias especificidades locales y regionales. Por lo tanto, no son necesariamente globales o "globalizadas". En este sentido, sostenemos que "la identidad no es generada porque se comparte un territorio común sino que es la identidad la que genera, instaura, el territorio" (Segato 2007: 87).

9 Instrumentos tradicionales de Bolivia y Perú legitimados en Argentina como parte del folclore del norte argentino.

10 Jackson 1983: 340.

11 Jackson 1983: 329. 


\section{LAS PERFORMANCES MUSICALES}

\subsection{Experiencia y emoción}

La emoción es un aspecto poco explorado en la bibliografía sobre música andina, aunque sus participantes continuamente se remitan a las sensaciones y sentimientos por los que atraviesan al tocar la música. La emoción es algo lingüístico, fisiológico y corporal. Los antropólogos pueden considerarla como una categoría cultural que engloba a todos estos elementos de distinto modo según sea el caso específico. Si bien no desconozco las implicancias de que "la experiencia y la expresión de la emoción no siempre tienen lugar en categorías explícitas"12, también es importante destacar que:

"Si las emociones, aunque no simplemente signos, son entendidas como experiencias de significado/sensación que están organizadas y mediadas por sistemas de signos, entonces al menos una traducción tentativa debería ser posible entre el sistema de significado y sensación bajo estudio, y el sistema que el etnógrafo comparte con el lector u oyente de la etnografía"13.

$\mathrm{Al}$ compartir experiencias comunes y estar enmarcados dentro de una historia que los une, los sikuris (sopladores de siku) pueden vivir la misma experiencia con similares emociones. Las podemos comprender como prácticas rituales desprendidas del discurso y las creencias que los convoca y los sentimientos comunitarios y de unión que los mancomuna, más allá de la experiencia transmitida. A pesar de esta premisa empática y colectiva, en algunos tocadores las emociones son expresadas más espontáneamente mientras que en otros, mayormente pertenecientes a grupos más tradicionalistas u "originarios" 14 , son enmascaradas, desviadas o emergen de distinto modo. Por eso, como las emociones no son universales transculturales, tampoco surgen de igual manera en un determinado momento de personas distintas, aunque el flow (flujo) de la performance así pretenda indicarlo ${ }^{15}$.

Este trabajo complementa escritos anteriores en los que argumento que, mediante un imaginario social utópico expresado en tanto visión del mundo andino, los participantes producen, renuevan y actualizan sentidos y emociones vinculados al "comunitarismo". Los distintos modos de acción y sus significaciones para cada proceso grupal inciden en las prácticas y presentaciones musicales, en el tipo de "subjetivación" que promueven y en los modos de representación musical de cada ensamble. Así, en estas agrupaciones existe un interés principal por generar estrechos vínculos entre la práctica musical y las emociones que supuestamente genera además de los valores y creencias que los sustentan, con el objetivo de producir nuevos modos de "vivir lo andino".

12 Leavitt 2007: 12.

13 Leavitt 2007: 21-22.

14 Podhajcer 2009.

15 El flow, flux o flujo son términos científicos para referir al curso que está tomando un evento o una performance. 
La performance musical posibilita a los tocadores un modo de vivir el sonido y el imaginario andino, vinculados ambos a una estructura musical andina establecida, basada en un diálogo intersubjetivo que articula música y corporalidad. Las modalidades sensoriales son vividas y revividas en cada performance, en tanto marco o frame, procesual y reflexivo ${ }^{16}$. En la espesura del sonido, los tocadores atribuyen sentidos a su práctica, generando procesos creativos, junto con innovar y elaborar un repertorio, una forma distinta de interpretación musical, un nuevo uso del cuerpo y nuevas pautas y estrategias para conservar su especificidad. Si bien el mundo interno de la ronda sikuri presenta diferencias estético-musicales derivadas de diferencias de estatus social -a nivel de ejecución de las distintas voces-, el comportamiento colectivo y "comunitario" de la ejecución musical transmite "igualitarismo" y "emotividad". De hecho, la construcción de esta coraza externa legitimada en el curso de la performance, opera como imagen de un corporativismo y una constitución grupal sólida frente a la audiencia espectadora ${ }^{17}$.

La ronda, el diálogo y el "tocar juntos" constituyen el carácter icónico-indexical como ícono de lo comunitario, que se va "cargando" de emociones en cada cita, en cada performance. Esta unidad social es asimismo una fuerza musical que la audiencia percibe. En palabras de Blacking ${ }^{18}$, la ronda constituye una "cultura afectiva" basada en una emotividad y modos creativos que se suceden en el curso de la performance, siendo intrínsecos -y por esta misma razón específicos- de la propia performance-sikuri. Como expresaba una sikuri, “...lo concreto es la música, es el estar. No hay alguien más importante que el otro. Necesitaba algo así, una comunidad igualitaria" (entrevista a Sikuri en 2008, integrante de "Sartañani Ayllu") ${ }^{19}$.

Los grupos de sikuris se caracterizan por una efectividad comunicativa desplegada en una performance caracterizada por un entrelazado musical, cuyo principal motor es la autorregulación intersubjetiva de todos los sopladores en la creación de armonía. Bajo estas premisas, se desarrollan también otros elementos fundamentales los que son indicativos del lugar del sentimiento y las emociones durante la ejecución. Según Bauman y Briggs ${ }^{20}$, estos son ejes funcionales a la ejecución, los que dependen de algunas variables cuyo marco referencial es la autoridad legitimada, que decide los discursos que se ejecutan y la continuidad de los valores tradicionales. El liderazgo tiene un efecto performativo por las cualidades afectivas preferenciales de la música sikuri y, por este motivo, crea identidades musicales, sociales y un ethos particular a cada tocador. A continuación analizaremos en qué

16 Goffman 1959: 114.

17 Goffman 1967: 24. Este corporativismo le permite al conjunto constituirse como comunidad con sus propias especificidades, roles internos, proyectos, etc. Por otra parte está lo que se denomina como "salvar las pifiadas" o errores individuales, ya que las variaciones de algunas cañas no alteran significativamente el sonido general, produciendo armónicos que se complementan. Esta performance del sonido musical reside justamente en la unidad sonora que logra concretar el conjunto.

18 Blacking 1979: XVII.

19 Mujer joven sikuri, de aspecto europeo y procedente de la capital de Buenos Aires. Ejecuta bombo y siku y es una de las "bombistas" del conjunto. Es música profesional de piano y hace más de siete años que integra el grupo. Junto con su pareja, acuden a marchas y manifestaciones.

20 Bauman y Briggs 1990: 70. 
consiste la ejecución sikuri, cómo se ponen en juego y se conectan los elementos estructurales musicales y, finalmente, las concepciones culturales de los tocadores sobre la música.

\subsection{Ronda, música y cuerpo}

La concepción dialógica del desplazamiento y el modo de ejecución del sikuri dependen de muchas variables que no solo pertenecen a lo musical, sino que también a determinados gestos y usos del cuerpo. En estas apropiaciones corporales de las músicas se producen reelaboraciones entendidas como traducciones culturales de tradiciones relocalizadas. Estas se suceden en los movimientos, en las formas de tocar -como el modo de "soplar la caña", en la mirada con la pareja y el grupo y en la fuerza o energía en la ejecución-, además de los modos de hablar sobre la práctica, entre otros. Esta concepción de "complementariedad" en el conjunto, que depende siempre de la respuesta y pregunta del/los otro/s, se construye en la acción misma de la práctica. Esto lo denomina Voloshinov ${ }^{21}$ como "la percepción activa del discurso ajeno”, la que concentra algunas tendencias del diálogo, como la orientación, la elaboración y la vivencia del mismo, que se suceden socialmente y acordes al contexto.

Existe en este tipo de ejecución un amplio despliegue de eficacia en la que la destreza musical y su efectividad tienen un rol primario en la formulación de los discursos ${ }^{22}$. Asimismo, durante la intensificación del diálogo musical, la repetición de la frase musical, como veremos a continuación, contribuye a crear un "exclusivo espacio perceptivo" que permite la experiencia del flow del evento y reafirmar, actualizando, la unidad musical principal ${ }^{23}$. Por estas razones, la repetición no es la reiteración de la unidad semántica, sino su reformulación, lo que permite que cada "parte" de la melodía sea única e irrepetible. En este sentido, la música anula el tiempo cotidiano para crear una nueva dimensión temporal, siendo su articulación acústica un elemento clave y de poder para la estructura performática ${ }^{24}$.

Durante la ejecución se realizan diferentes desplazamientos circulares que componen coreografías determinadas, por lo que, además de lo estrictamente musical, en lo corporal, discursivo y visual también adquieren un importante rol los métodos de enseñanza-aprendizaje ${ }^{25}$. En el vínculo entre el lenguaje musical y el lenguaje corporal -relacionados por la dialéctica de transformación entre el mundo andino y el cotidiano-, no solo cada melodía corresponde a un tipo de danza sino que además el sikuri improvisa distintos desplazamientos en cada caso según el contexto -lo que implica el hecho de ubicarse o no en un escenario y el

21 Voloshinov 1992: 157.

22 Bauman y Briggs 1990.

23 Qureshi 1994: 520.

24 Qureshi 1987: 1994.

25 Este espacio de traspaso de conocimiento es privilegiado para los artistas y, en particular, para los músicos, ya que se generan reciprocidades (relacionadas con el ayni-reciprocidad andina-), y por lo tanto, solidarias, las que forman parte de la cosmovisión y de las modalidades de estas expresiones artísticas. 
tipo de audiencia, entre otros- además de la conexión y mimesis entre los participantes. Los giros al final de cada vuelta de tema tampoco son casuales, ya que involucran nuevamente la concepción dual, siendo arka el giro en sentido de las agujas del reloj e ira el giro en dirección contraria ${ }^{26}$.

En la ciudad de Buenos Aires, las performances musicales se asemejan entre sí debido a que las agrupaciones presentan aspectos comunes, basados en pautas sociales y culturales transmitidas por los guías. Algunas melodías se inician con una secuencia de golpes simultáneos de todos los bombos presentes, generalmente no más de tres, dependiendo de la intensidad en el toque del bombo. Al finalizar esta secuencia se produce un silencio de pocos segundos. La pareja de zankas ${ }^{27}$ se miran entre ellos y a los bombistas, quienes en su conjunto darán comienzo a la melodía. En otros casos, y dependiendo del estilo musical, comienzan todos de forma simultánea 28 .

Toda melodía está compuesta por varias secciones o fragmentos que los tocadores denominan "partes del tema”. Una "vuelta del tema” implica tocar una vez toda la melodía. La performance del conjunto se basa en repetir por lo menos seis veces la melodía completa. Cada repetición tiene una energía distinta, basada en los movimientos de los músicos, en los bombistas que "marcan el ritmo" y en la intensidad que estos y los propios músicos le imprimen a cada "parte" ejecutada, mediante la cual los músicos adoptan un rol musical y toman su lugar en la ronda. Como bien ha señalado Bauman ${ }^{29}$, más allá de ser buenas o malas ejecuciones, es importante resaltar que si un grupo define su práctica como ejecución (que incluye una actuación y preparación frente a una audiencia), esta debe definirse como "variable en intensidad, como también en espectro".

El momento de ejecución colectiva es el más "profundo". Se inicia con la primera "vuelta" o "tocada" de la melodía en el sitio, sin moverse y con una energía mayor estimulada por el mismo hecho de estar comenzando a soplar. Es un momento de mucha interconexión musical, ya que los músicos vuelven a reconocerse en la ronda y a "comunicarse" con el instrumento, a sentirlo "parte propia". Las tres siguientes vueltas consisten en un giro de $180^{\circ}$ sobre su eje hacia la izquierda, para iniciar así una vuelta en conjunto de todos los músicos. En cambio, la cuarta "tocada del tema" implica una preparación. La misma se desarrolla con la ronda quieta, como en el inicio. Esta cuarta "tocada" antecede a la "tocada" final. La ronda colectiva "sabe" que siempre la última tocada es más ligera y requiere

26 Estos giros pueden abrirse hacia fuera o dentro del grupo. Véase Baumann 1996. Si bien esta concepción dualista es válida, muchos sikuris discuten actualmente su veracidad, argumentando que estos giros fueron "inventados" por el grupo musical "Ruphay", y que jamás fueron constatados en la práctica de los grupos tradicionales de Bolivia.

27 Zankas en voz quechua significa "adulto" o "mayor" y se refiere a las cañas grandes y largas generalmente ejecutadas por los guías o directores musicales. Para mayor detalle remito a Podhajcer 2011.

28 La primera modalidad caracteriza a los conjuntos puneños, mientras que ambas modalidades son características de los conjuntos de Buenos Aires. En aquellas melodías donde el bombo no comienza la melodía, el bombista-guía realiza un doble repique, todos se miran y mediante un gesto corporal hacia adentro de la ronda, comienzan simultáneamente a soplar (Podhajcer 2011).

29 Bauman 2002: 130. 
de más energía de parte del tocador. Por esta razón, al final de la cuarta tocada, aquellos cuerpos que estaban más "reposados" o "relajados" se incorporan con mayor tono muscular y miran fijamente a los guías y bombistas. Entonces todos concluyen abruptamente la última nota, para dar lugar a la "tocada" rápida del "tema". Esta requiere de una mayor precisión y atención del sikuri, quien debe "apurarse" sin equivocarse.

Los lenguajes corporal, sensorial y perceptivo son esenciales, debido a que los cuerpos que soplan deben seguir un ritmo colectivo que depende ampliamente de una interconexión musical. A mi parecer, este instante de pocos minutos compone un momento clave en la performance, debido a que marca un cambio en el ritmo musical y da inicio a la melodía. Por esta razón, como lo expresa Citro ${ }^{30}$, es relevante señalar "el hecho de que estos [rituales festivos] implican la percepción de estímulos sensoriales intensos y marcados así como el uso de técnicas corporales diferentes a las de la vida cotidiana".

Este momento de mayor interconexión ha sido definido por Turner ${ }^{31}$ como communitas, un estado que prioriza la unidad como una manera de experiencia. Por lo tanto, la elección de tocar en conjunto reside en la experiencia colectiva de bienestar y liberación. A partir de este concepto, es posible desarrollar determinadas significaciones asociadas así como los elementos primordiales para concretar el tipo de ejecución. En primer lugar, la noción de "atención" que cada uno de los sikuris desarrolla con su pareja instrumental y hacia el resto de los músicos privilegia la audición por sobre la visión, lo cual explica el que muchos sikuris señalen que prefieren tocar con los ojos cerrados. Sin embargo, se toque o no con los ojos cerrados, parecería que la comunicación por medio de los oídos permite dejar pasar la luz y participar visualmente ${ }^{32}$. La experiencia de oír y ver sonidos, sonoridades, vibraciones, fuentes de sonidos, modulaciones y "presencias" o fantasmas de otras personas, permiten la pérdida de la posición, de modo de abrir el "yo" hacia dentro y fuera de la ronda. Por lo tanto, la "disponibilidad" de cada músico produce que cada sonido personal sea de uno mismo y del otro, lo que permite surgir comportamientos no constituidos ni rígidos, sino que indiferenciados ${ }^{33}$.

Como lo expresa Ingold, los oídos son "imaginados de modo topográfico, como aberturas de la cabeza que realmente permiten penetrar y tocar las superficies más reclusas del ser" 34 . Las sensaciones de "poder tocar" el sonido e incluso de que los sonidos "se tocan" entre sí, raspándose, acariciándose, entrando en un baile espectral, componen la visión del mundo musical, explicado como un mundo "complementario" y "colectivo". Este mundo es la ronda musical, la que en cada performance vuelve a sembrarse y renace como un cuerpo nuevo. Así lo remarca el autor, cuando menciona el histórico desprecio de esta visión por parte de estudiosos clásicos de la cultura occidental, mientras que la audición siempre fue considerada

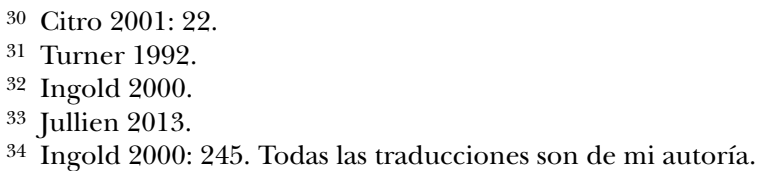


"calurosa, comunicativa y solidaria" 35 . La percepción es un modo de estar en el mundo que traspasa la razón, el cuerpo y el mismo mundo. Al mismo tiempo está en todos ellos y se constituye en una estrategia de perdurabilidad del conjunto musical, puesto que atraviesa al grupo en lo intersubjetivo y lo intercorporal. La preferencia de los sikuris por este saber práctico abreva acerca de la pertenencia y la recuperación de una atención visual y sonora en una constitución colectiva. La incorporación de técnicas musicales, movimientos coreográficos, códigos corporales, gestos y posturas componen la práctica sikuri. Así lo expresa Jackson ${ }^{36}$ :

"En este sentido, las técnicas del cuerpo pueden ser comparadas con técnicas musicales, ya que ambas nos transportan del mundo cotidiano de las distinciones verbales y separaciones categóricas a un mundo donde los límites se desdibujan y la experiencia se transforma. La danza y la música nos mueve para participar en un mundo más allá de nuestros roles habituales y a reconocernos como miembros de una comunidad, de un cuerpo común".

Según Qureshi, en estas prácticas el discurso no está escindido de la corporalidad, hasta el punto que las maneras de "experienciar" la corporalidad en colectivo dejan impresas "sensaciones corporales", a partir de las cuales podemos entender cómo otros experimentan y afirman su posición en el grupo, así como fuera de su entorno musical ${ }^{37}$. De esta manera, la multirreferencialidad musical implica una negociación de sentidos acerca del significado de la música y el poder de la música sobre la misma música.

Ahora bien, ¿por qué grupos más tradicionales postulan que la interconexión sucede cuando los instrumentos son "bien ejecutados", mientras que otros grupos consideran que la conexión sucede de todos modos, como si fuese un estado ad hoc de la práctica musical?

\section{3. ¿INTERCONECTADOS O "SONAR BIEN"?}

\section{1. "Hippies", "originarios" y un "mundo comunitario"}

Otro punto significativo que nos preguntamos es de qué modo -a partir del poder emocional que la música envuelve- los sonidos musicales pueden ser entendidos como el resultado directo de la ejecución instrumental, sin requerir mediaciones o simbolizaciones previas. De este modo, el lenguaje musical es similar al lenguaje corporal, ya que por medio de la actitud corporal o el gesto facial -al igual que al producir sonidos-, la mediación es directa, produciendo efectos a nivel emocional y energético ${ }^{38}$. Estas deducciones realizadas por Thomas Turino para la música

${ }^{35}$ Ingold $2000: 247$.

36 Jackson 1983: 338.

37 Qureshi 2000: 812.

38 El sonido sería central para dar sentido y para conocer, cuyo carácter de "agencialidad" conduce a vivenciar el mundo desde determinadas sonoridades (Qureshi 2000: 810). En este sentido, Feld concluyó que los kawali expresaban sus experiencias a partir de los sentidos de sus músicas, basadas 
andina, lo condujeron a explorar en diferentes prácticas expresivas de la música, la danza y los lenguajes proposicionales. Según él mismo,

"Mi tesis es que el poder de la música para crear respuestas emocionales y concretar identidades sociales y personales, se basa en el hecho de que los signos musicales son de los típicamente directos, del tipo menos mediado. La música involucra los signos del sentimiento y la experiencia antes que los signos de tipo mediacional que tratan acerca de algo más"39.

Basándose en la semiótica de Peirce, Turino definió que los símbolos son signos acerca de otras cosas, mientras que los íconos e índices son signos de identidad (semejanza, comunalidad) y de conexiones directas ${ }^{40}$. Los sonidos operan en estos niveles. Son los privilegiados en producir emociones que, mediando el transcurso del tiempo junto con una simbología específica y una verbalización de la relación entre un sonido particular y una imagen o sensación (como cuando la letra o la música de una canción permite evocar el paisaje andino, por ejemplo), pueden producir y convertir a la canción en el símbolo del paisaje al atardecer. Así lo transmite un sikuri:

"[Al tocar Jacha Laquitas ${ }^{41}$ pasan cosas. Son distintas sensaciones. Hay partes que desencadenan cosas que uno trae, por ay son buenas, a veces son malas. A veces se traen una emoción, a veces no. Depende de lo que vos le estás poniendo a la canción. Cómo te abrís a que te toque, así, adentro. Y cómo estás vos, las cosas que te pasaron. Tu vida, qué se yo. No podés esperar que al otro le pase lo mismo que a vos. No le va a pasar lo mismo, le pasan sus cosas. Está haciendo su experiencia con sus cosas. No es 'en esta parte nos ponemos todos. Arranca y arrancamos todos con fuerza porque estamos como subiendo el cerro' y luego cuando termina la vuelta, termina abajo 'es cuando baja el cerro'. Lo escuché muchas veces. Sí, estee 'cómo entenderla a la música'. No hay que entender la música. Hay que hacerlo bien y nada más. Hay que ejercitar el oído, ejercitar la parte y tratar de hacerlo igual. Después si querés viajar, si querés conocer, está buenísimo. Pero así viajando y conociendo, a vos te van a pasar tus cosas, aunque toques con los de allá. A ellos les van a pasar sus cosas y a vos te van a pasar las tuyas, de tu vida, trabajo, lo que sea. Con una misma melodía. Por ahí pasan cosas,,,son veinte tocadores y pasan veinte cosas diferentes. O dieciocho y los tocadores no se enganchan" (entrevista a Diego en 2009, sikuri, ex guía musical).

Si bien existen emociones despertadas por el vínculo que genera el tocador con una melodía particular, esta también puede ser utilizada para crear lazos imaginarios, convirtiéndose en un ícono étnico o político. Estos discursos indigenistas mencionados por mi interlocutor producen un relato legitimado acerca

en lo que denominó un "paisaje sonoro" (Feld 1986; 1988), con el que se identifican y que tienen como un ambiente natural y verdadero. Por eso aquellas melodías que "suenan como" otros sonidos de nuestra experiencia, vienen a conformar esa memoria emotiva de lo más próximo, familiar y comunal.

39 Turino 1999: 224, cursiva del autor.

40 Turino 1999: 228.

41 Género musical proveniente de la zona de Niño Corín, Departamento de La Paz, Bolivia. 
de las sensaciones que debe o puede producir la música andina en particular. Se deduce entonces que al ser un gran propulsor identitario, la música puede crear emociones, pero también permitir imaginarlas.

En esta construcción utópica del enunciado sonoro, distintas disputas de intereses producen brechas de orden ideológico y político que ejercen un rol importante en los eventos musicales, festivos y de accionar en la vía pública. Los mismos son polos de significado que se caracterizan como posicionamientos o significantes identitarios $^{42}$ y que, si bien fluctúan en los sujetos, se corresponden con brechas tradicionales del campo musical. De este modo, personas más tradicionalistas u "originarios" -generalmente migrantes obreros o trabajadores asalariados, de distintas nacionalidades ${ }^{43}$ - y aquellos menos tradicionalistas, los "hippies" -generalmente argentinos estudiantes universitarios o maestros, de distintas nacionalidades ${ }^{44}$ disputan el espacio público y el dominio de la "sabiduría" musical.

Los otros grupos, ni "originarios" ni "hippies", están integrados por jóvenes y adultos de clases populares, trabajadores asalariados y músicos profesionales. Comparten con los restantes grupos el objetivo de recuperar las músicas originarias y defender la música sikuri, sin embargo, también buscan la perfección musical, negando toda discusión "política" sobre la misma. Esto último es lo que los ubicaría "entre" los otros dos grupos señalados: no concilian con la "política" que hacen "los hippies" ni tampoco con el hermetismo y la evidente marcación étnica subrayada por "los originarios", quienes además oponen su trayectoria migrante al resto de la población argentina (en donde cuadran estos últimos dos grupos).

Estos "músicos profesionales" suelen ser "más tradicionalistas" y han conformado varios conjuntos. Si bien en su interior las personas no necesariamente sostienen este mismo discurso, el grupo exhibe un tipo de performance más "auténtica", a modo de ejemplo, ejecutar un estilo musical con la "ropa tradicional" y la coreografía "tradicional", cuestión que en los "hippies" no sucede (porque no desean "parecer andinos"), ni tampoco en los "originarios", quienes buscan una autenticidad grupal, la pertenencia a un grupo musical en Buenos Aires antes que a una ciudad o pueblo de Bolivia. La identidad diferencial está construida, en todo caso, en el origen étnico (aymara o quechua) y regional, antes que nacional. El discurso sobre esta identidad étnica es la que posiciona a un grupo "originario" en el ambiente.

Para los "originarios" y "músicos profesionales", que en su conjunto podemos denominar "más tradicionalistas", el "soplar bien" reside en "llenar bien la caña" con la forma particular de cada tocador y al mismo tiempo realizar correctamente el estilo, sin agregar ni "alargar" las notas. Los líderes o directores musicales transmiten que el instrumento se sopla bien cuando "se conoce" el instrumento, lo que implica usar bien el diafragma, capitalizar la fuerza y el aire puestos en la

42 Citro 2009.

43 Gran parte son migrantes procedentes de Bolivia e hijos descendientes de los mismos. Sin embargo, también hay migrantes procedentes de Perú y argentinos descendientes de europeos.

44 En su mayoría son argentinos descendientes de europeos que migraron a inicios del siglo XX a la Argentina. 
caña, captar las variaciones de la melodía y el ritmo ("escuchar bien la música"), "no perderse" (en las cañas) y conocer los estilos, entre otros. Cuando esto sucede, se produce la unificación en la ejecución entendida como una "conexión" porque, a pesar de que cada uno sopla distinto (direcciona el aire dentro de la caña de distinto modo), si los significantes anteriores están, la ejecución fluye y así también la forma personal de soplar. Por lo tanto, el "no sonar bien" comprende una falla musical que es relacionada con el desconocimiento y desinterés en el aprendizaje de la música sikuri o aymara.

Para los "hippies", en cambio, el "soplar bien" se vincula con la interconexión musical y es explicado como una "sensación" de bienestar corporal. El acento no está puesto en un mejoramiento del sonido o la obtención de armonía, sino en la conexión intercorporal por medio de los instrumentos. Por esta razón, algunos directores pronuncian frases como "No nos escuchamos", poniendo acento en el diálogo musical antes que en la forma de ejecución. Aquí transcribo tres citas de sikuris, las dos primeras más "tradicionales" y la última perteneciente a una formación más intercultural o "hippie":

“...En algunas tropas, como que lo ideal es que, todas las voces, las maltas, los chullis y las zankas vibren en un armónico similar (...) Si yo tengo unas maltas que están soplando y las zankas soplan poco, ahí se genera un desfasaje, que es lo que pasa en casi todas las bandas, que se ven por acá, o incluso en La Paz. Viste, igual lo ideal, viste, es muy difícil, que todas las voces jueguen con los mismos armónicos, que estén a la altura. La idea es escuchar en un sonido que uno no te des cuenta, o sea que no diferencies la tayka, la malta, la zanka y el chulli, o sea que sea todo un solo bloque, no, viste, un 'pu pu' y otro que está chiflando la caña, pero esto ya es más difícil.

A: Eso ya tiene que ver con el soplido, con el ataque.

$\mathrm{R}$ : Claro, que todos tengan un ataque similar, más que en cuanto a los cortes, para que se logre la armonía dentro del unísono, o sea, dentro de una sola caña" (entrevista a Rubén en 2011, guía de Wayramanta). ${ }^{45}$

"Afuera tiene que sonar la melodía, lo otro pasa adentro. El de afuera escucha la música... "pan, pan, pan, mirá que lindo poncho". Pero al de adentro le está pasando algo. Otras veces le gustó, la tocó,...está bueno, se conectó. Se conectó. Eso hay que buscar, conectarse. Te movilizó hacer algo. No lo estaba haciendo y de repente le dio ganas de hacer. Se conectó. Para bien, para mal de él, no sé. En ese momento sintonizó y encajó en el riel y se lo llevó, la música se lo llevó para un lado y después lo soltó. Con lo de él" (entrevista a Diego en 2008, sikuri, exguía).

45 Bellenger plantea similares apreciaciones sobre hacer "el Allin phuku o el arte de soplar correctamente" en la isla de Taquile: "La intención principal que emana de la ejecución comunitaria de los sikuri es soplar correctamente, de manera simultánea y continua en los tubos de los instrumentos de los diferentes registros para animarlos provocando la aparición de armónicas. Para lograrlo, cada participante debe dominar particularmente bien su soplo a fin de poder aumentar brevemente, después del primer ataque, la presión de aire insuflada en cada tubo. Cuando todo se desarrolla bien, la fluidez del 'diálogo' de los elementos ira y arka asociada al apilamiento armónico generado por los diferentes registros engendran una sonoridad global muy particular asimilada al canto o a la voz del conjunto de los siku así reunidos. Se busca este efecto para asimilarlo a la manifestación de la presencia de las fuerzas telúricas a Apu, invocados por los sikuri durante sus intervenciones" (Bellenger 2007: 141). 
"Al tocar, yo todo el tiempo siento una conexión. No sé si es por la forma que se respira...A mí me lleva a un plano, como tomarme en serio las cosas. Te conecta con la tierra. Me producen todos los sikuris una sensación de lo elemental, lo básico. ¿A vos te pasa eso? Porque a mí me parece que todos sentimos...Porque yo cuando empecé, es como eso de la rueda te marea, te parece denso, hay que esperar el tiempo del otro, y hacerlo otra vez y otra vez. No sé después empezás a tocar y no podes parar. Pero primero tenés que pasar ese proceso (entrevista a Angélica en 2008, sikuri legendaria).

Las referencias a "lo comunitario" y "la complementariedad" entre elementos, energías y personas están presentes en grupos menos tradicionalistas y más interculturales, quienes tienen una propuesta distinta a los preceptos tradicionales del ambiente, basada en una mirada latinoamericanista y democrática. Las diferentes proyecciones y motivaciones de los grupos redundan en cómo resuelven las estructuras musicales microconflictivas, entendidas como,

"combinaciones musicales que hacen que algo se escuche bien o se escuche mal", o sea "que si uno va muy alto, si en una línea melódica, cuán bajo está a esa melodía la otra voz, o si el instrumento acompañante hace un destiempo, un silencio, o hace una variación o un cambio de ritmo al que se esté efectuando" (entrevista a Diego en 2008, sikuri, ex guía).

Estas variaciones se resuelven con la autorregulación de la ronda, en donde los distintos tipos de soplido y ataque, armonía, inflexiones al soplar, repiqueteos, yerros, improvisaciones y otros elementos que componen la performance, son explicados a partir de discursos imaginarios sobre "lo andino", abrevando la necesidad de "escucharse", tomar decisiones en conjunto y generar un diálogo verbal más fructífero. En efecto, según una sikuri "si el grupo está mal, suena mal” y para el director de una banda, si la melodía es tocada más acelerada de lo que debiera, es un resultado de la influencia del ritmo de la ciudad en el modo de soplar de los sikuris. Las estructuras micromusicales son resueltas con destreza y percepción musical (expresadas en frases como "hay que escuchar"), lo que a su vez conduce al desarrollo de un oído "no occidental", o al menos a poder adquirir herramientas para desarrollar una escucha distinta a la occidental.

Por estas razones, para algunos conjuntos musicales las improvisaciones son situaciones aisladas que siempre implican una falta, un equívoco, un error o "no deben hacerse", es decir, no corresponde porque "altera la melodía" o "no queda bien". Así, recuerdo que, hace muchos años, una vez opté por "alargar la nota" al final de una melodía (en la que esto no suele hacerse) a lo cual el director de mi banda me hizo entender que no debía hacerlo más. Noté que lo que yo había hecho era trasladar algunos clichés de otros géneros (quizá del pop o del folclore) a estos estilos tradicionales y eso suponía una alteración del estilo. No era la primera vez que lo hacía, ni que proponía "arreglos" musicales. Sin embargo estos eran tomados naturalmente y los clichés fueron descartados.

Entonces comprendí que las variaciones en las intensidades o en el soplo (como "alargar la nota" cuando "no hay que hacerlo") deben ser decididas y coordinadas previamente en conjunto durante los ensayos y como parte de "arreglos" que 
"podemos" imprimir a nuestras ejecuciones. Esta apreciación reside en la forma fragmentada de ejecución por contestado, es decir, de manera trenzada y, por otro lado, en la construcción colectiva del hacer musical. Los imprevistos, en cambio, son "pifiadas", errores que pueden saldarse o no, dependiendo de la interconexión que el ensamble experimente en ese momento y la energía de la performance. En estos casos, la banda continúa tocando el tema como debe ser ejecutado, antes que tomar decisiones individuales que puedan afectar al sonido musical general. Por lo tanto, las improvisaciones como los imprevistos, son situaciones que alteran el sonido y "discuten" con los significantes hegemónicos sobre el ejecutar "como debe ser" o "correctamente" una melodía.

En efecto, podemos diferenciar dos significantes predominantes. El primero de ellos vincula el tipo de ejecución en ronda, con principios y preceptos tradicionales "colectivos". Esto nos lleva a postular "lo comunitario" y "la complementariedad" como visiones del mundo musical sikuri en Buenos Aires. El segundo, el acento en la destreza de ejecución del siku y el conocimiento sobre el o los estilos musicales que cada grupo ejecuta. Los géneros ejecutados de manera distinta a la tradicional son considerados degradaciones o "malas tocadas" del género. Si bien existe permeabilidad entre ambos significantes en los grupos tradicionalistas y no tradicionalistas, para los "hippies" y "originarios" los objetivos "comunitarios" propuestos son vertebrales, mientras que para el resto de los grupos (en cantidad menores), la motivación reside en la "ejecución correcta", asentada en un trabajo minucioso del estilo musical.

\subsection{Secreto y poder}

Es importante destacar que la búsqueda etnomusicológica y de matriz original se ha convertido en un discurso impregnante en el campo musical sikuri y ha retroalimentado los postulados tradicionales acerca de los secretos andinos aún no descifrados. Así, el secreto musical y ritual acerca del estilo musical y la comunidad indígena que lo toca en su festividad, ha sido resignificado como el canal hacia la "música aymara verdadera". Para los "hippies" y "originarios", los líderes guías cultivan la idea de un secreto no revelable e inalcanzable, lo cual vuelve aún más misteriosa y desafiante la experiencia de "hacer música sikuri". Con esto me refiero a que las apropiaciones esencialistas del "hacer musical" producen un tipo de agencia y de creatividad musical particulares, contribuyendo además a la expansión de estas prácticas culturales. En efecto, el secreto de los líderes actúa mediante relaciones de poder, disciplinas, rigurosidades "tradicionales" e intereses sostenidos y autorregulados por los discursos tradicionales. Estos permiten tanto la autorregulación de los secretos como de las estructuras musicales microconflictivas, imprimiendo efectos emocionales intensos en las subjetividades. De este modo, la intersubjetividad micromusical es generada en las motivaciones e intenciones de los tocadores por develar esos secretos y pertenecer y permanecer en el círculo, en la ronda. Estos secretos son estrategias de preservación de los grupos musicales y también de los propios roles musicales, los que deben ser interpretados correctamente, según la "disciplina” grupal específica. Por ende, el secreto puede ser 
develado a medida que las habilidades son adquiridas y, así y todo, es posible no "atravesar la bisagra" y nunca llegar al conocimiento de su significado.

En el microcosmos musical que constituye una particular y única visión del mundo, para algunos la interconexión es experiencial y sucede debido al tipo de música "comunitaria", mientras que para otros, solo hay conexión cuando "se toca bien”. Así, mi hipótesis es que la ronda y el tocar juntos funciona como un ícono de lo comunitario de la utopía andina compartido por todos, el cual mediante las distintas performances sikuris, por diferentes grupos, se va cargando de otros significantes indexicales. A este respecto, valga el testimonio de Angélica en 2008:

"Para mí lo más valioso del siku es eso de que si o si tenés que... porque no es un acuerdo de palabra, que vos y yo nos tenemos que poner de acuerdo. Pero si vos estas acelerada, venís de trabajar cansada y yo vengo lenta, ¿no? hasta que respiramos igual y hasta que,... es algo elemental que tenemos que tener, una energía que funcione en la misma dirección. Y eso es una cosa que, materialmente, te trae un aprendizaje, porque tu cuerpo se tiene que acondicionar, no es que tu cabeza entienda que tenés que contestar... Tu cuerpo tiene que respirar igual que el otro. Para mí que realmente es una de las armas de transmisión cultural porque tiene todos los elementos".

Para nuestra interlocutora -quien ha integrado distintos grupos de sikuris-, en la repetición, el propio cuerpo "tiene que respirar igual que el otro" y es en esta interconexión corporal y musical donde se teje la intersubjetividad. Según Merleau-Ponty, siempre percibimos desde un mismo lugar puntual espacial y temporal, desde una misma perspectiva e historia personal, ya que "nuestro 'esquema corporal' es un resumen de nuestra experiencia corporal (pero) no se limita a los contenidos afectivos y fortuitamente asociados en el curso de nuestra experiencia, sino que, en cierto modo, los precede y hace posible su asociación”46.

En segundo lugar, esa percepción sucede desde el cuerpo con otros cuerpos, desde los cuales, moviéndonos, nos extendemos hacia el entorno, hacia los objetos y hacia lo que queremos hacer, ya que "el esquema corporal es una toma de conciencia global de mi postura en el mundo intersensorial" ${ }^{47}$. Esto implica, finalmente, que el cuerpo no se enfrenta a un universo por explorar, sino que está enlazado al mundo ${ }^{48}$. De manera que la performance musical permite que algunos sujetos se apropien de determinadas experiencias vinculadas con su historia e incluso les permite cambiar ciertos hábitos e incorporar otros nuevos. Esta intercorporalidad musical siembra continuamente cuerpos nuevos (personales y colectivos), construidos en el curso del "tacto musical" con el otro, como si ira y arka estuviesen adheridas corporalmente. Esta "sensación" de que la dualidad iraarka está basada en un "pegamento musical” hace del instrumento una extensión del propio cuerpo.

\footnotetext{
46 Merleau-Ponty 1945: 116. Traducción de mi autoría.

47 Merleau-Ponty 1945: 116.

48 Aschieri y Puglisi 2010.
} 
Al poner la música en diálogo con otras dimensiones propias del horizonte contextual musical, las prácticas musicales pueden analizarse desde una propuesta antropológica que conjugue el estudio de la corporalidad con las emociones. Así, la experiencia musical permite a los sikuris un espacio "comunitario" de estar en el mundo, debido a que sienten que pueden cambiar o transformar sus maneras de conocer y vivir. La música "es un sitio privilegiado para conservar la memoria cultural, pero para otros, se convierte en un sitio de contienda para reconstruir el pasado -para 'vivir las memorias de otras personas'”, según Regula Qureshi ${ }^{49}$. Comparto con la autora que al recuperar la subjetividad junto con un estudio de las abstracciones colectivas corporizadas en un instrumento musical como objeto "efectivo" y, por otro lado, con su sonido particular, accedemos a una agencia localizada en las construcciones del pasado y los cambios políticos y afectivos. En efecto, podemos introducirnos en el universo de las comunidades afectivas, en donde también es reinventada la música y sus contextos de actuación ${ }^{50}$.

\section{BREVES REFLEXIONES}

Este trabajo se propuso como objetivo abordar las prácticas de música sikuri desde su performance, los significantes y discursos hegemónicos y cómo pueden interpretarse a partir de la interconexión corporal y musical alcanzada. En primer lugar, me propuse captar en profundidad los estados de percepción corporizados musicalmente de manera colectiva, proponiendo un enfoque vivencial a partir de las inscripciones corporales de mis experiencias previas y una etnografía participativa.

En segundo término, me focalicé en cómo estos lenguajes musicales corporizados pueden ser entendidos como técnicas aprendidas miméticamente por patrones de uso del cuerpo, determinados por el propio cuerpo y el cuerpo de los otros, en una constante tensión por evitar fricciones de la estructura musical. Así, he resaltado la tendencia colectiva a la autorregulación y a la alineación de energías que analizamos en los modos de percepción y atención, característicos de estas prácticas aprendidas socialmente.

En tercer lugar, observamos cómo estas variaciones musicales y corporales modelan y transforman la performance en cada evento, produciendo nuevos comportamientos, movimientos corporales y códigos miméticos que redundan en procesos afectivos sensoriales en la ronda musical y, en términos más amplios, en la música sikuri en la ciudad.

\section{BIBLIOGRAFÍA}

\section{Aschieri, Patricia y Rodolfo Puglisi}

2010 "Cuerpo y producción de conocimiento en el trabajo de campo. Una aproximación desde la fenomenología, las ciencias cognitivas y las prácticas corporales

49 Qureshi 2000: 827.

50 Qureshi 2000: 830. 
orientales", en Silvia Citro (coordinadora). Cuerpos plurales. Ensayos antropológicos de y desde los cuerpos. Buenos Aires: Editorial Biblos, pp. 127-148.

BAUMAN, RichaRD

2002 "Disciplinarity, Reflexivity, and Power in Verbal Art as Performance: A Response", The Journal of American Folklore, CXV/455 (invierno), pp. 92-98.

Bauman, Richard y Charles L. Briggs

1990 "Poetics and Performance as Critical Perspectives on Language and Social Life", Annual Review of Anthropology, XIX/1, pp. 59-88.

Baumann, Max Peter

1996 “Andean Music, Symbolic Dualism and Cosmology”, en Max Peter Baumann (editor).Cosmología y música en los Andes. Madrid: Iberoamericana, pp. 15-65.

Bellenger, Xavier

2007 El espacio musical andino. Perú: IFEA.

Benencia, Roberto y Gabriela Karasik

1995 Inmigración limítrofe: los bolivianos en Buenos Aires. Buenos Aires: Paidós.

BLACKING, JoHN

1979 The Performing Arts - Music and Dance. La Haya, Holanda: Mouton.

Caggiano, Sergio

2005 Lo que no entra en el crisol: inmigración boliviana, comunicación intercultural y procesos identitarios. Buenos Aires: Prometeo.

Citro, Silvia

2000 "El análisis del cuerpo en contextos festivo-rituales: el caso del pogo", Cuadernos de Antropología Social, XI/12, pp. 225-242.

2001 "El cuerpo emotivo: de las performances rituales al teatro", en Elina Matoso (compiladora). Imagen y representación del cuerpo. Serie Ficha de Cátedra, Teoría General del Movimiento. Buenos Aires: Publicaciones de la Facultad de Filosofía y Letras, Universidad de Buenos Aires, pp. 19-34.

2009 Cuerpos significantes. Travesías de una etnografía dialéctica. Buenos Aires: Editorial Biblos.

FELD, STEVEN

1986 "Sound as Symbolic System: The Kaluli Drum”, en Charlotte Frisbie (editora). Explorations in Ethnomusicology: Essays in Honor of David P. McAllester. Detroit: Detroit Monographs in Musicology, No 9, Papua Nueva Guinea, pp. 147-158.

1988 “Aesthetics as Iconicity of Style, or 'Lift-Up-Over Sounding':Getting into the Kaluli Groove", Yearbook for Traditional Music, XX/1, pp. 74-114.

Gavazzo, Natalia

2005 "El patrimonio cultural boliviano en Buenos Aires: usos de la cultura e integración”, en Alicia Martín (compiladora). Folklore en las grandes ciudades: Arte popular, identidad y cultura. Buenos Aires: Libros del Zorzal, pp. 37-76.

GOFFMAN, ERIC

1959 The Presentation of Self in Everyday Life. Londres: Penguin Books.

1967 Interaction Ritual: Essays on Face-to-Face Behavior. Nueva York: Doubleday \& Company, inc. 
GRIMSON, ALEJANDRO

2005 Relatos de la diferencia y la igualdad: Los bolivianos en Buenos Aires. Buenos Aires: Eudeba.

2006 "Nuevas xenofobias, nuevas políticas étnicas en la Argentina”, Migraciones regionales hacia la Argentina: Diferencia, desigualdad y derechos. Compilado por Alejandro Grimson y Elizabeth Jelin. Buenos Aires: Prometeo, pp. 69-97.

INGOLD, TIMOTY

2000 "Pare, olhe, escute - um prefácio", The Perception of the Environ-ment. Essays in Livelihood, Dwelling and Skill. Londres: Ed. Routledge. pp. 243-287.

JACKSON, MichaEL

1983 "Knowledge of the body, Man", XVIII/2 (invierno), pp. 327-345.

Jullien, François

2013 Estar disponible. Recuperado de http://www.pagina12.com.ar/diario/psicologia/9-218246-2013-04-18.html

LEAVITT, JoHN

2007 "Meaning and Feeling in the Anthropology of Emotions", American Ethnologist, XXIII/3 (agosto), pp. 514-539.

Merleau-Ponty, Maurice

1945 Phénomenologie de la perception. Paris: Ed. Gallimard.

Mugraza, Susana

1985 "Presencia y ausencia boliviana en la ciudad de Buenos Aires", Estudios Migratorios Latinoamericanos, I/1 (diciembre), pp. 98-106.

PODHAJCER, Adil

2009 "Pienso que todavía no hay consciencia: Originarios vs hippies. Narrativas musicales andinas en la ciudad de Buenos Aires", Jornadas de Estudios Indígenas y Coloniales, Centro de Estudios Indigenas y Coloniales, 26 al 28 de noviembre. Jujuy, Argentina. En prensa.

2011 "El diálogo musical andino: emoción y creencias en la creatividad de conjuntos de 'música andina' de Buenos Aires (Argentina) y Puno (Perú)", Latin American Music Review, XXXIII/1 (invierno), pp. 269-293.

QuReshi, Regula

1987 "Musical Sound and Contextual input: A Performance Model for Musical Analysis", Ethnomusicology, XXXI/1 (invierno), pp. 57-85.

1994 "Exploring Time Cross-Culturally: Ideology and Performances of Time in the Sufi Qawwali”, The Journal of Musicology, XII/4, pp. 491-528.

2000 "How does Music mean? Embodied Memories and the Politics of Affect in the Indian 'Sarangi'”, American Ethnologist, XXVII/4 (invierno), pp. 805-838.

Segato, Rita

2007 La nación y sus otros. Raza, etnicidad y diversidad religiosa en tiempos de Políticas de la Identidad. Buenos Aires: Prometeo libros.

Turino, THOMAS

1999 "Signs of Imagination, Identity, and Experience: Peircian Semiotic Theory for Music”. Ethnomusicology, XLIII/2 (verano), pp. 221-255. 
2003 "Nationalism and Latin American Music: Selected Case Studies and Theoretical Considerations", Latin American Music Review, XXIV/2, pp. 169-209.

TURNER, Victor

1992 The Anthropology of Performance. Nueva York: PAJ Publications.

Voloshinov, Nikólaievich V.

1992 El marxismo y la filosofía del lenguaje. Madrid: Alianza. 